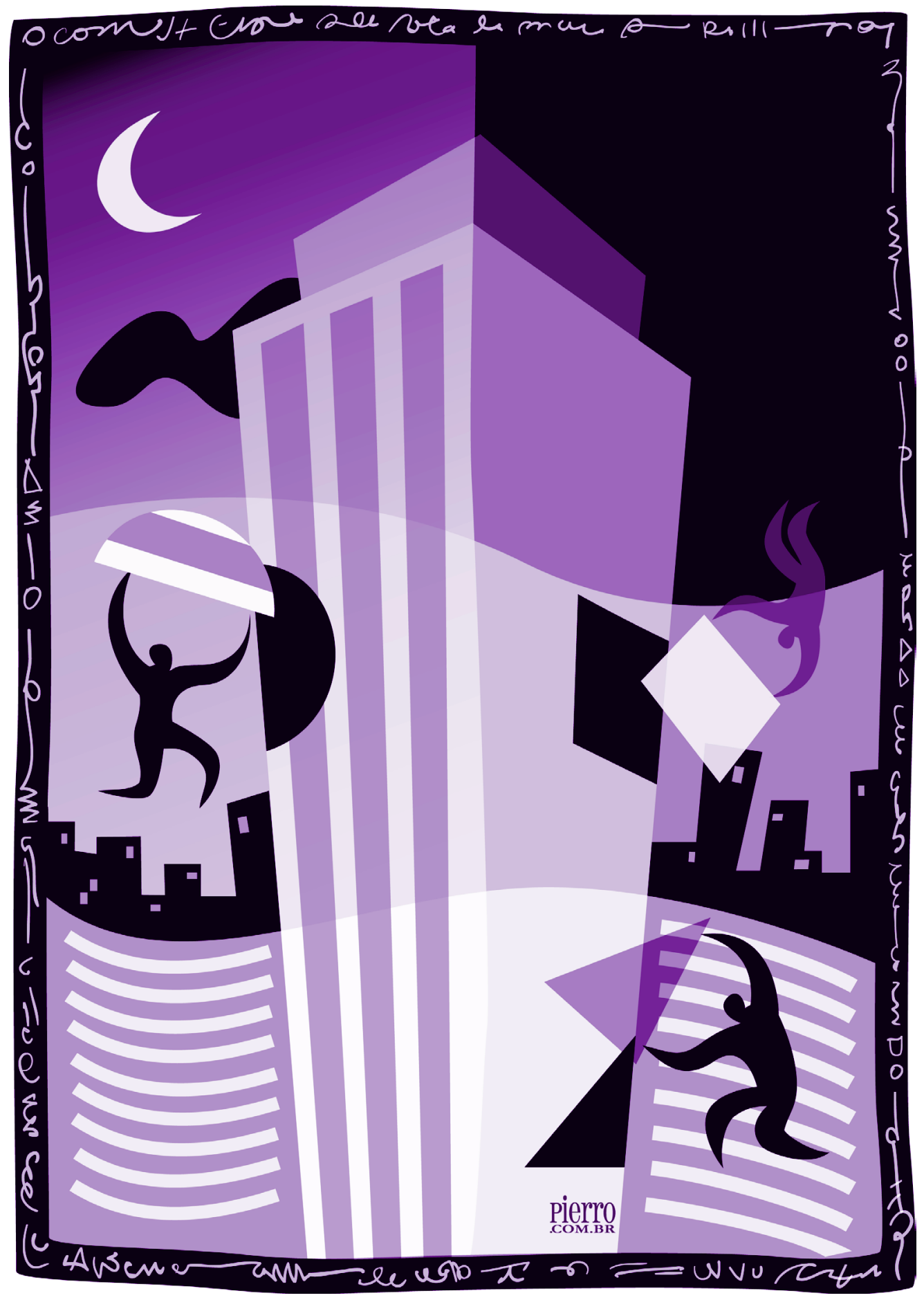




\section{O mosaico da avaliação em Relações Públicas}

Linda Childers Hon

- Professora Associada (PhD)

Departamento de Relações Públicas

College of Journalism and Communications Gainesville, Florida, EUA

-Ihon@jou.ufl.edu 
Resumo

Este artigo traça um panorama dos itens relacionados à mensuração da eficácia das Relações Públicas. A autora argumenta que o valor das Relações Públicas para as organizações reside na construção e na sustentação de relacionamentos públicos. A metáfora de um mosaico é utilizada a fim de ilustrar como as várias ferramentas de mensuração - desde resultados e impactos comunicacionais até indicadores de relacionamento - formam o contexto completo da avaliação em Relações Públicas.

PALAVRAS-CHAVE: RELAÇÕES PÚBlicas • COMUNICAÇÃo ORGANIZACIONAL • AVALIAÇão • MENSURAÇÃo • EFICÁCIA • GESTÃo dE RELACIONAMENTOS

\section{Abstract}

This paper provides an overview of issues related to measuring the effectiveness of Public Relations. The author argues out that the value of Public Relations to organizations and society is building and sustaining public relationships. A mosaic metaphor is used to illustrate how various measurement tools - from communication outputs and impacts to relationship indicators - form the complete picture of Public Relations evaluation.

KEY WORDS: PUBLIC RELATIONS • ORGANIZATIONAL COMMUNICATION • EVALUATION • MEASUREMENT • EFFECTIVENESS • RELATIONSHIP MANAGEMENT

\section{Resumen}

Este artículo traza un panorama de los ítems relacionados con la medición de la eficacia de las Relaciones Públicas. La autora argumenta que el valor que tiene las Relaciones Públicas para las organizaciones, reside en la construcción y en el mantenimiento de relaciones con los públicos. La metáfora de un mosaico se usa con el fin de ilustrar el modo en que las diversas herramientas de medición, desde resultados e impactos comunicacionales hasta indicadores de relaciones- forman el contexto completo de evaluación en Relaciones Públicas.

PALABRAS CLAVES: RELACIONES PÚBLICAS • COMUNICACIÓN ORGANIZACIONAL • EVALUACIÓN 
mensuração da eficácia em Relações Públicas tem sido vista como uma "solu-
ção mágica" (silver bullet) para a área, pois permite aos seus usuários identifi-
carem o valor de sua contribuição para a organização (Grunig, Grunig e Dozier, 2002). Pesquisas acadêmicas demonstram que resultados de medição e avaliação são considerados como prioridade número um para os profissionais da área (McElreath e Blamphin, 1994). Uma leitura cuidadosa dos tópicos apresentados em conferências nacionais reforça a validade desta revelação ${ }^{1}$. Estudos realizados com profissionais internacionais apontam para a mesma conclusão - os profissionais acreditam que a avaliação em Relações Públicas e a comunicação do valor da função para a alta gerência são as principais preocupações da área (Synnott e McKie, 1997).

O propósito desta discussão é propiciar uma visão ampla das questões relacionadas com a eficácia da medição das Relações Públicas, apresentando várias e diferentes perspectivas para considerar essa medição e oferecendo um guia prático de como a avaliação desta área se insere no seu gerenciamento estratégico. Também leva em consideração a evolução da avaliação das Relações Públicas a partir da medição dos efeitos de curto prazo da Comunicação até a avaliação dos relacionamentos da organização com os públicos. A metáfora "mosaico" é utilizada para ilustrar como diversas ferramentas de medição são utilizadas para formar o quadro completo da eficácia das Relações Públicas.

Este texto propõe ainda que a prática de Relações Públicas, como gerenciamento eficaz dos relacionamentos de uma organização com seu público estratégico, é a tarefa primordial de seus profissionais. Mediante esta prática, as Relações Públicas podem reconhecer seu potencial e a oportunidade de causar um impacto positivo nas sociedades que lhes concedem legitimidade como função profissional. Embora o foco principal desta discussão seja a construção e a prática da teoria das Relações Públicas nos Estados Unidos, seus conceitos e princípios deveriam idealmente transcender a diversidade cultural e ser susceptíveis de adaptação em diferentes locais.

\section{Definindo eficácia}

Antes de tratar dos detalhes da avaliação das Relações Públicas, é importante identificar as diferentes perspectivas da definição de eficácia dessa área. Existem pelo me-

1 Ver, por exemplo, http://www/prsa.org/_Advance/seminars/index.asp?indent=apr0 
nos três escolas relativas ao pensamento sobre as Relações Públicas que podem ser identificadas na literatura específica e na prática profissional. Cada uma delas traz consigo diferentes implicações para a avaliação das Relações Públicas.

A primeira é a abordagem retórica que define a eficácia das Relações Públicas como a comunicação que cria suficiente significado compartilhado entre organizações e públicos para que objetivos mútuos sejam alcançados (Heath, 1992). Estudiosos e profissionais que atuam nessa perspectiva tendem a se preocupar em verificar se as mensagens da organização são persuasivas e se os públicos são suscetíveis, em sua atitude e comportamento às mesmas, de forma a atender aos objetivos da organização.

Embora alguns estudiosos tenham observado que as Relações Públicas retóricas sejam um processo de mão dupla, por meio da qual organizações e públicos criam um significado compartilhado (Heath, 2001), a maioria das pesquisas dessa perspectiva não avaliou a presença ou a eficácia de uma dialética de via dupla entre organizações e públicos. De fato, muito da prática de Relações Públicas, ao menos nos Estados Unidos, parece sugerir que seu papel é utilizar principalmente a comunicação de mão única para persuadir públicos a aceitar mensagens organizacionais e agir de forma a servir aos interesses das organizações. Uma análise das campanhas premiadas, apresentadas pela Associação Norte-Americana de Relações Públicas - PRSA, a mais proeminente associação profissional dos Estados Unidos, sustenta este argumento (Ahles, 2003).

A segunda abordagem para definir a eficácia em Relações Públicas é a perspectiva crítica (L’Etang e Pieczka, 1996). Aqui o papel das Relações Públicas é utilizar a Comunicação para transformar os sistemas organizacionais e da sociedade com o objetivo de reconciliar desequilíbrios de poder que privilegiam alguns grupos, enquanto inibem o poder de outros.

Embora os próprios profissionais aprovem esse sistema de valor, poucos são os casos encontrados que surgiram dessa perspectiva. Para a maioria, essa perspectiva obteve a adesão de muitos estudiosos das Relações Públicas, muitos dos quais não residem nos Estados Unidos (embora alguns deles estejam lecionando ou atuando profissionalmente nos Estados Unidos).

Alguns desses estudiosos abraçam o pós-modernismo e procuram dar um caráter ativista para as Relações Públicas (Holtzhausen, 2000). Dentro dessa abordagem, a eficácia é determinada pela extensão com que as Relações Públicas oferecem oportunidades para grupos marginalizados ou menos poderosos para se expressarem e impactarem as decisões das coalizões dominantes das organizações. Esta coalizão refere-se a um grupo de pessoas que tem a autoridade formal ou que, por meio de uma base informal de poder, lideram a organização ao deter o poder de tomada de decisão (Mintzberg, 1983). 


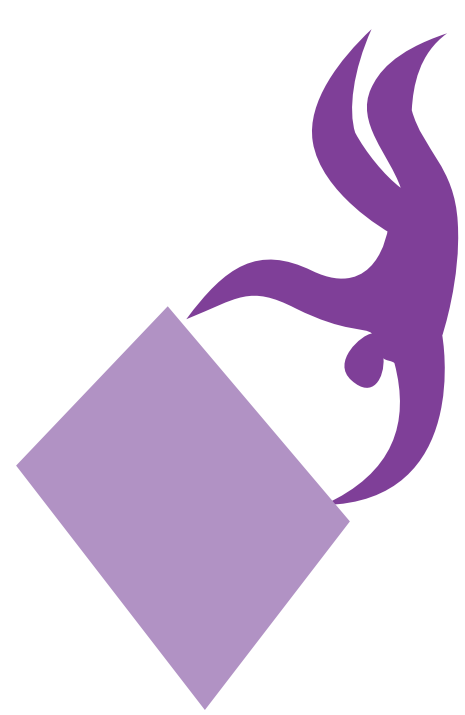

Relacionada à abordagem crítica, alguns estudiosos acreditam que as Relações Públicas, particularmente nas multinacionais baseadas na América do Norte, produzem submissão não coercitiva de públicos mediante a influência hegemônica (Roper, 2005). Nesta perspectiva, as Relações Públicas se engajam na comunicação simétrica de duas mãos com os públicos (equilibrada para assegurar que os interesses das organizações e dos públicos sejam atendidos) para atender questões de transparência e expectativas de responsabilidade social. Mas, na realidade, essas tentativas são, de fato, cosméticas porque a agenda capitalista e pró-globalização das organizações permanecem inalteradas.

De forma semelhante, alguns estudiosos rejeitaram a premissa de que as Relações Públicas e o desenvolvimento da Comunicação apoiadas pelos Estados Unidos servem para criar uma "sociedade civil" que aumenta o poder dos públicos nativos nos países que são o objeto desses esforços (Dutta-Beergman, no prelo). O argumento é que o manto da pró-democracia da sociedade civil é uma cortina de fumaça usada para justificar as invasões imperialistas nos países do Terceiro Mundo com o objetivo de alcançar "mobilidade de capital além das fronteiras nacionais" e assegurar que "as nações do Terceiro Mundo participem do mercado econômico e abram suas economias para investimento estrangeiro e comércio exterior" (Dutta-Bergman, no prelo). Ao fazer isso, grupos já reprimidos como o proletariado, camponeses, mulheres e povos indígenas, tornam-se ainda mais marginalizados (Rogall, 1998).

Uma última perspectiva crítica é a "Escola Latino-Americana de Relações Publicas" (Molleda, 2001). Nesta visão, a eficácia das Relações Públicas está relacionada em como a profissão promove "o progresso pessoal e o bem-estar", protege os direitos humanos e atende "as necessidades essenciais dos povos" (Molleda, 2001). Aqui, as organizações e os públicos entendem que são dependentes no desenvolvimento de suas condições individuais. Assim, a medição da eficácia é focalizada na avaliação do entendimento, do consenso e de atitudes integradas, bem como até que ponto os esforços de Relações Públicas ajudaram a superar a desconfiança. Essa perspectiva é sugerida como a mais coerente para aquelas sociedades com amplas transformações políticas e econômicas relacionadas à "privatização, à desregulamentação, às desigualdades sociais crescentes e à integração de mercado” (Molleda, 2001). 
A maioria dos argumentos apresentados neste texto tem sua origem na terceira perspectiva. Esta é distinta, porém não mutuamente exclusiva das preocupações sociais inerentes nas perspectivas críticas ou alheia às realidades da prática profissional que as intenções persuasivas da comunicação retórica explicitam. Uma teoria integrada de eficácia organizacional exige que a função das Relações Públicas deva incorporar os valores dos públicos estratégicos nos objetivos organizacionais "para que a organização atinja os objetivos de maior valor para seus públicos estratégicos" (Molleda, 2001). A materialização dessa perspectiva é o desenvolvimento e a manutenção de relacionamentos duradouros de qualidade com essa clientela.

Essa perspectiva integrada implica que a medição da eficácia seja mais complicada do que documentar a realização de metas por parte da organização (ou, inversamente, do público). Uma abordagem integrada assume que Relações Públicas eficazes são medidas pela dimensão com que uma organização reconhece seus públicos estratégicos (como, por exemplo, na legitimação de sua existência, suas preocupações e expectativas) e desenvolve relacionamentos positivos com esses grupos. Relações Públicas eficazes são, portanto, simbólicas, no âmbito da Comunicação, bem como comportamentais (Grunig e Huang, 2000). Em outras palavras, existe coerência entre o que a organização diz e o que faz.

O desafio para profissionais e estudiosos de Relações Públicas é entender essas diferentes perspectivas para praticar Relações Públicas e o que elas implicam para a medição da eficácia. Esse desafio assume uma reconciliação com as implicações éticas de cada abordagem. Este trabalho argumenta que a abordagem integrada deveria ser o papel normativo social para a prática eficaz e ética das Relações Públicas. Subjacentes na referida perspectiva estão os papéis de ativista e de consciência social para as Relações Públicas, vislumbrados por estudiosos pós-modernos e da Escola LatinoAmericana de Relações Públicas. Um modelo integrado também possui o potencial para atender os ideais comunitários (Grunig, 1993) onde as Relações Públicas são a função que ajuda organizações e suas comunidades a unirem seus interesses para atender necessidades sociais mais abrangentes.

Quando as Relações Públicas adotam uma abordagem integrada para conseguir a eficácia organizacional, seu valor para organizações e para a sociedade é otimizado. Ao reconciliar os objetivos das organizações com seus públicos, as Relações Públicas ajudam organizações a tornarem-se mais éticas e eficazes. A prática constrói relacionamentos que conduzem a comportamentos positivos que apoiam a missão organizacional, tais como investimentos, empregos, doações e vendas sem violar as expectativas do público e as preocupações com a responsabilidade social (Kruckeberg e Starck, 1998). Talvez, até mais importante seja o valor que as Relações Públicas oferecem ao prevenir comportamentos negativos como greves, processos judiciários, boicotes dos consumidores, regulamentação governamental e cobertura prejudicial da imprensa, que venha a resultar em crises de mal gerenciadas e pressões por parte de grupos ativistas (Grunig et al., 1992). 


\section{O valor das Relações Públicas eficazes}

Há um debate contínuo nas comunidades profissionais e acadêmicas dos Estados Unidos sobre se a contribuição das Relações Públicas para as organizações pode ser avaliada por meio de valores financeiros. Existem evidências para documentar que altos executivos acreditam que o retorno sobre investimento em Relações Públicas é elevado (Grunig et al., 1992). Houve também pesquisa qualitativa com profissionais e altos dirigentes de organizações em que se descobriu a viabilidade de vincular o sucesso de Relações Públicas com resultados financeiros (Grunig et al., 1992). Ao mesmo tempo, esses profissionais e executivos freqüentemente expressaram hesitação ao fazê-lo por causa da impossibilidade de isolar os efeitos das Relações Públicas de outros fatores explanatórios (a serem examinados mais adiante).

Uma abordagem que foi sugerida para ajudar os profissionais a articularem melhor o valor financeiro das Relações Públicas é a compensação da variação (Grunig, Grunig e Dozier, 2002). Aqui, solicita-se aos gerentes que estimem quanto a organização gostaria de pagar para evitar ou para obter determinados resultados. As quantias representam, basicamente, o valor do resultado final de Relações Públicas para a organização.

A despeito do potencial desta abordagem, o momento atual das Relações Públicas nos Estados Unidos não é propício para se implementar tais técnicas de avaliação de risco e de resultados. De fato, deixou-se de lado a discussão de uma solução mágica a respeito de valores monetários para um processo educacional a respeito de indicadores não financeiros da eficácia das Relações Públicas (Hon, 1997). O argumento utilizado aqui é que indicadores não financeiros tais como a reputação da organização, fidelidade dos empregados, confiança do consumidor e dos acionistas e boa vontade da comunidade são indicadores mais significativos das Relações Públicas bem-sucedidas. Isto porque esses indicadores, de fato, funcionam como representações de relacionamentos positivos com públicos-chave.

\section{Relações Públicas como um experimento}

Antes de examinar a abordagem de relacionamento na medição da eficácia das Relações Públicas com mais detalhes, alguns dogmas básicos de avaliação devem ser apresentados. É útil pensar na administração estratégica das Relações Públicas como um experimento (pré-teste-tratamento / pós-teste). A estrutura experimental serve como modelo para o processo de Relações Públicas (Ehling, 1992 e Hillsdale et al., 2002), freqüentemente relacionado com o uso dos termos como: pesquisa, objetivos, programa, avaliação e sustentação (Likely, 2005). Pesquisa formativa é realizada para efetuar as medições básicas e para efetuar o planejamento de programa ou campanha. Objetivos mensuráveis são elaborados para especificar resultados desejados. Comunicações estratégicas e táticas são programadas por serem consideradas mais 
eficazes para conseguir os objetivos propostos, além de ter custo compatível. A certa altura do programa ou da campanha, é realizada uma avaliação para medir se os objetivos estão sendo atingidos. Finalmente, planos de sustentação são implementados com o objetivo de manter os relacionamentos positivos obtidos com a campanha ou com o programa realizado.

O "verdadeiro" experimento também inclui uma comparação realizada entre um grupo de controle que não participou do programa ou campanha com o grupo participante (Hendrix, 2004). Contudo, poucas são as situações de Relações Públicas que permitem este rigor de avaliação devido às limitações de tempo e de orçamento e, possivelmente, da falta de interesse por parte de clientes e organizações em ter este nível de certeza sobre os efeitos das Relações Públicas.

Uma frustração para profissionais é a inabilidade de mostrar qualquer ligação causal direta entre o tratamento (programas e campanhas) e efeitos medidos - por exemplo, aumento do entendimento e confiança. O fato que a prática das Relações Públicas ocorre em situações complexas e não num laboratório esterilizado, o que obriga seus profissionais a reconhecer que seus esforços podem sempre ser auxiliados ou impedidos por fatores externos, tais como os outros esforços de Comunicação da organização (Marketing, publicidade, campanhas de financiamento), eventos concomitantes que poderiam resultar em um desaceleramento da iniciativa de Relações Públicas ou em retirar o debate da agenda dos meios de comunicação e, logicamente, as crises que requerem imediata e constante atenção e que, portanto, desviam recursos de programas ou campanhas em andamento. Um outro fato importante é que os efeitos dos esforços de Relações Públicas podem vir a longo prazo e, assim, são impossíveis de mensurar e de se considerar como uma justificativa imediata das despesas de Relações Públicas.

\section{Medidas de eficácia das Relações Públicas}

A despeito de toda a preocupação na indústria e nos meios acadêmicos nos Estados Unidos sobre a dificuldade de captar o valor das Relações Públicas, atualmente exis-

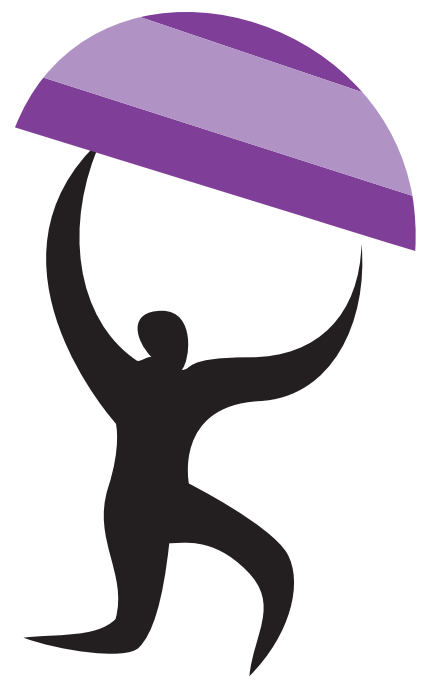


tem várias técnicas e ferramentas de avaliação. Estas podem ser relacionadas ao referido mosaico em que todas as peças formam o quadro completo da avaliação das Relações Públicas. Contudo, nenhuma peça consegue se sustentar sozinha. Dentro de uma abordagem integrada para conseguir a eficácia organizacional, todas essas ferramentas contribuem em diferentes níveis para avaliar se e em qual extensão a comunicação organização-público está sendo construída e mantendo relacionamentos de qualidade.

Qualquer que seja a peça do mosaico, a avaliação das Relações Públicas tende a concentrar-se em documentar evidências bem-sucedidas de processo / resultado ou de impacto $^{2}$. Embora algumas pesquisas e literatura prática de Relações Públicas incluam o trabalho com os meios de comunicação como uma etapa intermediária, é importante esclarecer a diferença que existe entre resultado e impacto.

\section{Resultados das Relações Públicas}

Historicamente, o resultado das Relações Públicas é avaliado documentando-se as atividades que as pessoas desenvolvem quando implementam programas e campanhas (Broom e Dozier, 1990). Em outras palavras, profissionais medem a distribuição/ disseminação de materiais de comunicação produzidos e tarefas realizadas. Aqui, por exemplo, profissionais registram o número de notícias enviadas, anúncios publicados, número de eventos especiais realizados, número de cartas ou petições enviadas, número e duração de reuniões com membros dos públicos estratégicos, e assim por diante. Embora este nível de documentação seja mais rotineiro e possa parecer sem importância, o ato de documentar os resultados e avaliar se eles são atingidos é importante para a própria credibilidade dos profissionais de Relações Públicas e de outros profissionais quanto a questões do tempo e esforço dispendido. Esta documentação também pode servir como importante justificativa para os gastos realizados, caso os objetivos do programa ou campanha não atinjam os resultados esperados devido a circunstâncias imprevistas.

\section{Divulgação junto aos meios de comunicação}

Muito da avaliação de Relações Públicas esteve focalizada num outro passo que não é facilmente compreendido como resultado ou impacto e que, freqüentemente, foi erroneamente entendido como prova de impacto. Estimar a quantidade e a qualidade de colocação de notícias na mídia dominou muito o processo de avaliação das Relações

2 W. K. Lindenmann (acessado em 3/21/05). "Guidelines and standards for measuring the effectiveness of PR programs and activities". Disponível no site http://www.instituteforpr.com/measurement_and_evaluation. phtml?article_id=2003_guide_pr_effectiveness. 
Públicas nos Estados Unidos. Discutir as razões por trás disso está além do escopo deste artigo. Entretanto, as raízes da busca de divulgação, a crença no poder dos meios de comunicação de massa para afetar a opinião pública e seu comportamento, como foi evidenciado na propaganda bem-sucedida nos tempos de guerra e o treinamento jornalístico de muitos profissionais das Relações Públicas do século XX são, sem dúvida, fatores que contribuíram para se acreditar que o bem-sucedido trabalho com a mídia é a principal prova das Relações Públicas eficazes.

A maior parte da medição neste nível conta o número de clippings ou efetua as medições de tempo no ar e os índices de distribuição na mídia. São também avaliadas medições tais como circulação, cobertura de públicos, leitores e níveis de audiência. O objetivo básico é fornecer evidências de que a Comunicação Organizacional foi disseminada de forma eficaz nos canais da mídia (Broom e Dozier, 1990).

Exposição na mídia também é freqüentemente avaliada quanto à sua qualidade: a cobertura foi positiva, negativa, neutra? Houve destaque para a notícia? Atendeu os objetivos de comunicação do programa ou da campanha? Colocou a organização em destaque em relação a seus concorrentes? O cálculo de quanto uma notícia teria custado à organização, quando ela é publicada gratuitamente, é uma técnica ainda usada por profissionais nos Estados Unidos. As limitações desta técnica conhecida como "centimetragem" estão bem documentadas (Hendrix, 2004) (por exemplo, uma matéria publicada espontaneamente em um jornal que é lido por formadores de opinião não pode ser comparada com o custos da mesma matéria se houvesse sido paga).

\section{O impacto das Relações Públicas}

Uma mudança conceitual aconteceu na indústria das Relações Públicas nos Estados Unidos no que se refere a medir a colocação na mídia como meio para um fim (resultado) e não como um fim em si (impacto). Uma importante indicação dessa mudança é que a PRSA agora proíbe que qualquer programa ou campanha de Relações Públicas seja selecionado para o seu prêmio, o Silver Anvil (A Bigorna de Prata) a menos que a campanha inclua medições de impacto do programa (Bromm e Dozier, 1990). Em outras palavras, a colocação de informações na mídia tornou-se mais um processo de medição que pode ou não levar a efeitos desejados de Relações Públicas em organizações e públicos. Ao mesmo tempo, embora seja dado muito crédito entre profissionais para Relações Públicas como comunicação de duas mãos e a noção de que a missão primordial das Relações Públicas é a construção de relacionamentos (Hon, 1997), os vencedores das premiações de campanha da PRSA demonstram que a avaliação para a maioria ainda está focalizada na medição dos efeitos da comunicação de mão única sobre públicos-alvo e na avaliação desses efeitos contra os objetivos da organização (Hon, 1997). 
Assim, muito da avaliação de impacto de Relações Públicas ocorre no nível do programa como pesquisas ou estudo de grupos focais ou observações de comportamento (ou pesquisa/ estudo de grupos focais que registra autonarrativas de comportamento). Por exemplo, programas medem, freqüentemente, níveis de conhecimento sobre mensagens críticas de uma campanha nos seus públicos-alvo. Campanhas também podem incluir medições efetuadas por meio de itens da escala Likert (concorda muito até discorda muito) e/ ou escalas tipo Diferencial Semântico que oferecem dois opostos polarizados (bom - ruim) e solicitam que os entrevistados indiquem onde sua atitude está situada no campo das respostas (Ahles, 2003). Medições de comportamento são provavelmente as mais diretas formas de avaliação nas Relações Públicas porque podem freqüentemente ser observadas mediante telefonemas, número de doações efetuadas, redução do número de reclamações de clientes, aumento na participação em programas de voluntariado pelos funcionários, aumento de vendas, valor das ações da companhia etc.

É importante salientar, contudo, que este ciclo de comunicação (conhecimento $\rightarrow$ atitude $\rightarrow$ comportamento) de avaliação de Relações Públicas é muitas vezes implícito e não bem documentado mediante evidências formais - em resumos publicados sobre a prática de Relações Públicas bem como em "histórias" dos profissionais a respeito de seus esforços anteriores (Broom e Dozier, 1990). Uma análise mais profunda revela que profissionais não são bem-sucedidos na avaliação de atitudes específicas e freqüentemente tecem conclusões infundadas na avaliação dos indicadores de exposição e/ ou resultados de conhecimento e comportamento desejado (Hon, 1997). As realidades da prática, tais como a dificuldade e o custo de avaliar atitudes, sem dúvida, tornam-se uma forte restrição nos métodos de avaliação utilizados pelos profissionais, dado o fato de que eles (as) não foram adequadamente treinados (as) nas ferramentas de medição das ciências sociais ou pelo fato de que seus clientes / organizações não queiram patrocinar pesquisas de atitude se os resultados comportamentais são aparentes (Ahles, 2003).

\section{Avaliação das Relações Públicas como comunicação retórica}

Um outro ponto sobre avaliação de Relações Públicas serve como um aparato de retórica para os profissionais de Relações Públicas no sentido de que lhes permite efetuar reivindicações jurisdicionais sobre a profissão (Austin, Pinkleton e Dixon, 2000). Tais reivindicações são elaboradas para evidenciar que as Relações Públicas possuem um corpo único de conhecimentos e habilidades específicas que não são nem tão simplistas nem rotineiras, para que profissionais de outras áreas possam ter o direito de reivindicar atuação nesse território.

Diante dessa realidade, talvez não seja surpreendente que uma quantidade relevante da avaliação de Relações Públicas focalizou resultados de alta visibilidade, tais como colocação na mídia e a tendência de se valer das avaliações independentes ou das compilações de dados a respeito da opinião pública (Pieczka, 2000). Essas medições, em- 


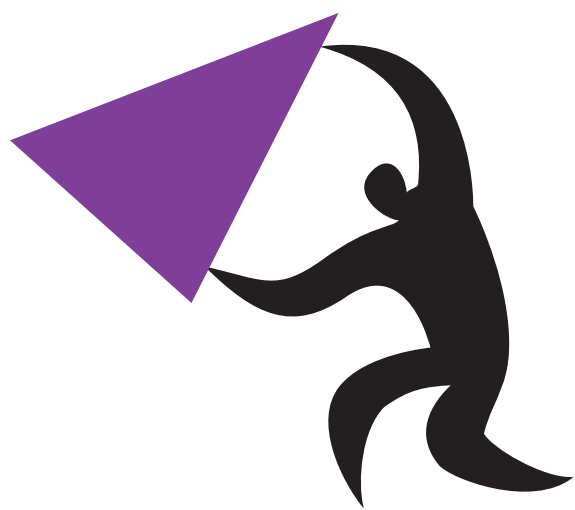

bora perifericamente relacionadas com a cadeia de comunicação implícita dos programas e campanhas de Relações Públicas, podem ser consideradas como medições relevantes daqueles que contratam ou orçam serviços de Relações Públicas. Em outras palavras, a eficácia das Relações Públicas está nos olhos de quem a vê. O desafio para os profissionais dessa área, portanto, é negociar com sucesso o significado do valor das Relações Públicas para suas organizações. Ainda mais, este texto argumenta que para a função se legitimar como uma profissão e contribuir para a responsabilidade social da organização, este valor é mais bem compreendido mediante o gerenciamento bem-sucedido nos relacionamentos organização/ público.

\section{Avaliação dos relacionamentos com os públicos}

Este argumento traz à tona a questão do que medir se o gerenciamento eficaz dos relacionamentos é o modelo normativo para a prática e avaliação das Relações Públicas. Tentativas anteriores de compreender os relacionamentos da organização/ público surgiram de pesquisas sobre co-orientação, isto é, um termo teórico que no contexto das Relações Públicas refere-se à abrangência na qual organizações e públicos expressam congruência cognitiva e comportamental sobre os problemas e oportunidades das Relações Públicas (Pieczka, 2000). Muito freqüentemente, as variáveis utilizadas para avaliar a co-orientação são exatidão, compreensão e acordo. Isto é, ambas as partes do relacionamento possuem percepções exatas da posição do outro? Eles compreendem a posição do outro? Eles estão de acordo com a posição do outro? A função das Relações Públicas neste contexto é utilizar a comunicação para reduzir "brechas" na exatidão, compreensão e acordo.

Contudo, poucos exemplos da vida real podem ser encontrados na avaliação das Relações Públicas que adotam explicitamente a perspectiva de co-orientação. Ainda mais, uma boa parte das pesquisas sobre "brechas" realizadas por alguns profissionais dos Estados Unidos também se enquadram nesta categoria (McLeod e Chaffee, 1973). Aqui, tipicamente, a pesquisa ou o estudo de grupos focais é realizado para estabelecer se uma organização e público (s) possuem informação exata sobre a posição um do outro e compreende a posição do outro. É relativamente fácil visualizar como qualquer brecha identificada representa um problema ou oportunidade de Relações Públicas. Por exemplo, se organizações e públicos pensam que possuem uma posição de destaque quanto à exatidão, compreensão e acordo quando de fato não a têm, podem surgir mal-entendidos e o relacionamento pode ser prejudicado. 
Desde o desenvolvimento da teoria da co-orientação, abordagens mais sofisticadas para o pensamento e a medição de relacionamentos públicos foram desenvolvidas. Embora tentativas na medição de relacionamentos públicos sejam relativamente novas, esta abordagem para a avaliação nas Relações Públicas é talvez a mais importante componente do mosaico. Isto porque a medição do relacionamento permite aos profissionais capturar o valor das Relações Públicas num nível mais elevado de desempenho do que meramente medir resultados da Comunicação e impacto sobre conhecimento, atitude e comportamento.

\section{Os papéis do profissional e a avaliação de Relações Públicas}

O valor da medição de relacionamentos pode ser mais bem entendido considerandose os diferentes papéis que os profissionais desempenham e os padrões de desempenho pelos quais se tornarão responsáveis em cada nível. A maioria dos estudos sobre papéis nas Relações Públicas, realizados nos Estados Unidos, focaliza a distinção entre técnicos e gerentes (Broom, 1982).

Técnicos são os profissionais encarregados do resultado da comunicação no departamento de Relações Públicas - por exemplo, escrever, editar, elaborar publicações, desenvolver e manter o website da organização. Aqui a avaliação obviamente está orientada na documentação do resultado e na medição da eficácia dos produtos de comunicação relativos à qualidade de processo, tempos das atividades e custo (Broom, 1982).

Gerentes distinguem-se dos técnicos por seu poder na tomada de decisão (Broom, 192 e Dozier, 1984). Em outras palavras, gerentes podem influir na política e têm a condição de decidir quanto à alocação de recursos, ao passo que técnicos se encarregam de implementar as decisões de outros. Além de medir o impacto do programa, gerentes são responsáveis pela administração do projeto no que tange à alocação de recursos, gerenciamento de fornecedores e serviço a clientes (Broom, 1982).

Uma distinção, porém, pode ser efetuada dentro dos níveis de gerentes que inclua o papel do profissional de nível executivo ${ }^{3}$. Este nível mais alto é importante ser lembrado porque quando os profissionais desempenham este papel, são responsáveis pelo papel de liderança que as Relações Públicas exercem no desenvolvimento e manutenção de relacionamentos positivos com a clientela estratégica e a vinculação entre esses relacionamentos com a reputação e o desempenho da organização. Como identificar e medir esses relacionamentos é o assunto do próximo item deste trabalho.

3 F. Likely, (acessado em 3/21/05). Communication and pr: Made to measure. Disponível no site http://www.instituteforpr.com/measurement_and_evaluation.phtml. 


\section{Por que se formam os relacionamentos com os públicos?}

Relacionamentos organização/ público formam-se porque as organizações causam conseqüências sobre grupos de indivíduos e vice-versa (Grunig e Hunt, 1984). O tipo mais básico de relacionamento organização/ público é entre uma organização e um público específico. Entretanto, muitas combinações de relacionamentos públicos existem (por exemplo, coalizões entre vários públicos que se reúnem para apoiar ou se opor a uma ou mais organizações) (Grunig e Hunt, 1984).

Assim, o primeiro passo para avaliar os relacionamentos públicos é a análise ambiental (environmental scanning), que é um termo geral para qualquer pesquisa primária ou secundária que ajuda as organizações a entender "O que está acontecendo?” em seus ambientes interno e externo e o que poderia afetar a organização (Grunig e Huang, 2000). A análise ambiental pode tomar diversas formas, como pesquisas formais ou pode ser mais informal, como o monitoramento da cobertura da mídia nas tendências do setor industrial ou outros assuntos. O objetivo é identificar questões, problemas e oportunidades e quem são os públicos-chave com quem a organização necessita desenvolver relacionamentos. Logicamente a organização já tem seus públicos-chave tais como seus empregados, que também se encontram como relacionamento público com a organização.

\section{Medição de relacionamentos com os públicos: processo}

Estudiosos das Relações Públicas adotaram de pesquisadores que estudam comunicação interpessoal e resolução de conflitos o desenvolvimento de uma lista de estratégias de manutenção de relacionamentos que eles defendem como mais eficazes para a construção e a manutenção de relacionamentos públicos de qualidade. A medição dos resultados de relacionamentos de qualidade, que será apresentada mais adiante, fornece a mais significativa avaliação da eficácia de Relações Públicas (Broom e Dozier, 1990). Porém, a utilização de estratégias de manutenção por organizações e públicos pode ser documentada e compreendida como medição de processos que sugerem, no curto prazo, se os esforços de comunicação estão levando a impactos positivos de longo prazo sobre os relacionamentos (Hon e Grunig, 1999).

Positividade é a primeira estratégia de manutenção de relacionamentos que as organizações e os públicos necessitam praticar e avaliar. Essa estratégia refere-se a tudo o que uma organização ou público faz para tornar o relacionamento mais positivo ou agradável para a outra parte (Hon e Grunig, 1999). De fato, neste papel como função de serviço, a maioria das atividades de Relações Públicas nas organizações é elaborada para expressar positividade para os públicos.

Outra importante estratégia de gerenciamento de relacionamento é a abertura (Grunig e Huang, 2000). No contexto do relacionamento pessoal, amigos são as pessoas que 
compartilham sentimentos e revelam segredos uns aos outros. E com o passar do tempo, à medida que o fazem, o relacionamento se desenvolve. Relacionado com a abertura está o acesso (Grunig e Huang, 2000). Qualquer relacionamento de qualidade é baseado na noção de que as pessoas no relacionamento têm acesso umas às outras. Em outras palavras, colocam-se de fato à disposição do outro.

Em um relacionamento com os públicos, os mesmos princípios de abertura se aplicam. Assim, organizações e públicos que desejam construir e sustentar relacionamentos positivos criam oportunidades para abertura propiciando acesso uns aos outros. Para uma organização, esta abertura pode ser algo tão simples e rotineiro como o compromisso de responder pronta e diretamente solicitações via e-mail ou por telefone (por exemplo, não filtradas por secretárias e pessoal de relações com clientes, quando apropriado). Outros tipos de abertura e acesso podem ser mais estruturados, tais como websites interativos, reuniões abertas com executivos da organização e open houses e visitas na organização.

Outra estratégia de manutenção de relacionamento é oferecer garantias, que se refere a tentativas das partes no relacionamento em assegurar a outros que elas e suas preocupações são legítimas (Grunig e Huang, 2000). Garantias também podem envolver tentativas, pelas partes no relacionamento, na demonstração de seu compromisso com o relacionamento (Grunig e Huang, 2000).

Um exemplo no fornecimento de garantias aos públicos é exemplificado pela Monsanto (Grunig e Huang, 2000). A companhia tem sido o alvo predileto para as preocupações de públicos ativistas com respeito à biotecnologia e a alimentos geneticamente modificados. O Compromisso da Monsanto é uma tentativa de responder a essas preocupações. No Compromisso, a companhia promete diálogo, transparência e compartilhamento. Os exemplos mais evidentes das garantias concedidas, porém, são encontrados nas promessas dos beneficios do documento: "Entregaremos produtos de alta qualidade, benéficos a nossos clientes e ao meio ambiente, com ciência sólida e inovadora, e gerenciamento cuidadoso e eficaz". E respeito: "Respeitaremos os interesses religiosos, culturais e éticos das pessoas em todo o mundo. A segurança de nossos empregados, as comunidades onde operamos, nossos clientes e o meio ambiente serão nossa mais alta prioridade” (Hon, no prelo).

Compartilhar tarefas (sharing of tasks) é outra estratégia de manutenção de relacionamento (Grunig e Huang, 2000). Esta estratégia implica que as pessoas num relacionamento compartilham todas e quaisquer responsabilidades criadas por decisões mútuas tomadas no relacionamento (Grunig e Huang, 2000). Obviamente, os públicos esperam que as organizações compartilhem responsabilidade por qualquer tarefa requerida em cuidar de questões que lhes concernem (por exemplo, o meio ambiente, as oportunidades e as condições de emprego envolvimento organizacional e apoio para instituições educacionais e culturais). 
Rede de relacionamentos (networking) também ajuda a fomentar relacionamentos públicos positivos (Hon e Grunig, 1999). Num relacionamento interpessoal, a rede de relacionamentos significa dedicar um tempo com amigos comuns a fim de angariar apoio e tornar o relacionamento agradável. Num relacionamento público, as organizações constroem redes de relacionamento com os mesmos grupos que se relacionam com seus públicos, tais como sindicatos, grupos comunitários e ambientalistas (Grunig e Huang, 2000). A eficácia das organizações nessa estratégia de manutenção de relacionamento é evidenciada mediante o número e qualidade de contatos com esses grupos (Hon e Grunig, 1999).

Na maioria dos relacionamentos, o conflito inevitavelmente ocorre. A chave para a manutenção do relacionamento eficaz está em como as organizações e públicos lidam com o conflito. Os enfoques que as partes utilizam para encarar o conflito podem ser documentadas e avaliadas para estabelecer sua eficácia. Argumenta-se aqui que as estratégias de "interesse mútuo" utilizadas para a solução de conflitos são as mais eficazes porque valorizam a construção e a manutenção de relacionamento positivo de longo prazo, em vez de procurar soluções de curto prazo ou ganhos à custa da outra parte envolvida (Hon e Grunig, 1999).

Estratégias de interesse mútuo incluem cooperação, ser incondicionalmente construtivo e expressar desejo de negociar no formato "ganha-ganha" ou "sem acordo" (Plowman, 1998). A cooperação é sugerida como a estratégia ideal porque busca um padrão ético mais elevado e é a que mais tem possibilidades de ser eficaz. Aqui, uma organização e o público trabalham juntos para negociar seus interesses e atingir soluções benéficas mútuas dentro do contexto de um interesse público maior. Em algumas situações, porém, uma organização e o público podem ser incapazes de encontrar uma solução mutuamente benéfica. Neste cenário, uma administração eficaz de relacionamentos poderia sugerir ser incondicionalmente construtivo ou de negociar no formato ganhaganha ou sem acordo (Plowman, 1998). Uma organização ou público é incondicionalmente construtiva quando percebe que manter um relacionamento positivo é tão importante como o fato de desistir de algumas de suas posições vale a pena, mesmo que o outro lado não seja recíproco. "Sem acordo" significa que ambos os lados concordam em discordar. É uma estratégia de manutenção de relacionamento eficaz porque preserva o relacionamento enquanto deixa aberta a oportunidade de encontrar uma solução "ganha-ganha" no futuro.

\section{Medindo relacionamentos com os públicos: impacto}

Organizações e públicos que participam em estratégias eficazes de manutenção de relacionamentos devem ser capazes de vincular esses processos a resultados significativos, ou seja, relacionamentos positivos, de longo prazo. Indicadores de relacionamentos de qualidade podem ser avaliados por meio de pesquisas quantitativas e qualitativas. 
Duas publicações produzidas para o Instituto de Relações Públicas, na Universidade da Flórida, fornecem o mapa de como profissionais podem avaliar o estado dos relacionamentos organizacionais com os públicos. É desnecessário reproduzir aqui o conteúdo desses documentos que especificamente relacionam a medição (entrevista e itens num questionário) uma vez que se encontram acessíveis no site http:www.instituteforpr.com sob os títulos research ("pesquisa") e relationships ("relacionamentos"). Independente desse fato, as principais variáveis que são a base da avaliação de relacionamentos públicos positivos devem ser discutidas.

Confiança é talvez o mais importante indicador de um relacionamento de qualidade e pode ser definido como o nível de confiança da organização ou do público em e na vontade de revelar-se para o outro (Grunig e Huang, 2000). Confiança possui várias dimensões, que devem ser mensuradas para captar o conceito mais amplo, isto é, integridade, a crença de que a outra parte é justa e imparcial; segurança, a crença de que a outra parte fará o que diz que irá fazer; competência, a crença de que uma organização tem a capacidade para fazer o que diz que irá fazer (Grunig e Huang, 2000).

Outro resultado de relacionamento é o controle da mutualidade, que se refere ao grau em que as organizações e públicos concordam em quem possui o legítimo poder para influenciar uns aos outros (Hon e Grunig, 1999). Embora o equilíbrio do poder em qualquer relacionamento possa ser desigual, a variável crítica de relacionamentos positivos é se os desequilíbrios são percebidos por ambas as partes como aceitáveis e não como forçados.

Satisfação é outro indicador de qualidade da qualidade de relacionamentos (Grunig e Huang, 2000). Satisfação pode ocorrer quando as organizações e os públicos sentemse favoravelmente com relação ao outro porque as expectativas positivas sobre o relacionamento são reforçadas, quando os benefícios do relacionamento são mais importantes do que os custos ou quando as organizações e os públicos acreditam que os comportamentos de manutenção de relacionamentos do outro são positivos (Grunig e Huang, 2000).

Finalmente, comprometimento é a dimensão na qual as organizações e os públicos acreditam que o relacionamento merece dispêndio de energia para ser mantido e promovido (Grunig e Huang, 2000). Comprometimento pode ser uma conexão emocional ou estar relacionado a buscar uma determinada linha de ação (Meyer e Allen, 1984). Juntos, esses resultados de relacionamento formam os últimos elementos do mosaico da avaliação das Relações Públicas que este texto procurou apresentar. Sugere-se que todos os níveis de avaliação das Relações Públicas contribuam para formar o mosaico, mas os últimos indicadores de relacionamentos apresentados oferecem a maior promessa para a realização e a medição da eficácia das Relações Públicas nas organizações e para a sociedade. 


\section{Bibliografia}

AHLES, C. B. Campaign excellence: A survey of Silver Anvil winners compares current PR practice with planning, campaign theory. The Public Relations Strategist, 9, 2003, p. 46-53.

AUSTIN, E. W.; PINKLETON, B. E. e DIXON, A. Barriers to public relations program research. Journal of Public Relations Research, 12(3), 2000, p. 211-233.

BROOM, G. M. e DOZIER, D. M. Using research in Public Relations. Applications to program management. Englewood Cliffs, NJ: Prentice-Hall, 1990.

BRoom, G. M. A comparison of sex roles in Public Relations. Public Relations Review, 8(3), 1982, p. 17-22.

DOZIER, D. M. Program evaluation and roles of practitioners. Public Relations Review, 10(2), 1984, p. 13-21.

DUTTA-BERgman, M. Public Relations and Civil Society: Not so civil after all. Journal of Public Relations Research, 17(3), no prelo.

EHLING, W. P. Estimating the value of Public Relations and communication to an organization. In J.E. Grunig (ed.). Excellence in Public Relations and communication management, 1992, p. 617-638.

GRUNIG, J. E. Image and substance: From symbolic to behavioral relationships. Public Relations Review, 91(2), 1993, p. 121-139.

GRUNIG, J. E. e HUANG, Y. From organizational effectiveness to relationship indicators: Antecedent of relationships, Public Relations strategies, and relationship outcomes. In J. A. Ledingham e S. D. Bruning (eds.), Public Relations as relationship management. Mahwah, NJ: Erlbaum, 2000, p. 23-54.

GRUNIG, J. E. e HUNT, T. Managing Public Relations. New York: Holt, Rinehart, and Winston, 1984.

GRUNIG, J. E.; GRUNIG, L. A.; DOZIER, D. M.; EHLING, W. P.; REPPER, F. C. e WHITE, J. Excellence in Public Relations and communication management. Hillsdale, NJ: Erlbaum, 1992.

GRUNIG, L. A.; GRUNIG, J. E. e DOZIER, D. M. Excellent Public Relations and effective organizations. Mahwah, NJ: Erlbaum, 2002.

HEATH, R.L. The wrangle in the marketplace: A rhetorical perspective of Public Relations. In E. L. Toth e R. L. Heath (eds.). Rhetorical and critical approaches to Public Relations. Hillsdale, NJ: Erlbaum, 1992, p. 3-15.

. A rhetorical enactment rationale for Public Relations: The good organization communicating well. In R.

L. HEATH (ed.). Handbook of Public Relations. Thousand Oaks, CA: Sage, 2001, p. 31-50.

HENDRIX, J. A. Public Relations cases. Belmont, CA; Wadsworth, 2004.

HILLSDALE, N. J.; ERLBAUM; GRUNIG, L. A.; GRUNIG, J. E. e DOZIER, D. M. Excellent Public Relations and effective organizations. Mahwah, NJ: Erlbaum, 2002.

HOltZhausen, D. R. Postmodern values in Public Relations. Journal of Public Relations Research, 12(1), 2000, p. 93-114.

HON, L. C. e GRUNIG, J. E. Guidelines for measuring relationships in Public Relations. Gainesville, FL: Institute for Public Relations. Disponível no site http://www.instituteforpr.com/relationships.phtml, 1999. 
HON, L. C. What have you done for me lately? Exploring effectiveness in Public Relations. Journal of Public Relations Research, 9(1), 1997, p. 1-30.

. Negotiating relationships with activist publics. In K. Fitzpatrick e C. Bronstein (eds.). Perspectives on ethics in Public Relations: Responsible advocacy. Thousand Oaks, CA: Sage, 1997.

KELLY, K. S. Stewardship: The fifth step in the Public Relations process. In R. L. Heath (ed.). Handbook of Public Relations. Thousand Oaks, CA: Sage, 2001, p. 279-289.

KRUCKEBERG, D. e STARCK, K. Public Relations and community: A reconstructed theory. New York: Praeger, 1988.

L'ETANG, J. e PIECZKA, M. Critical Perspectives in Public Relations. London: International Thomson, 1996.

LIKELY, F. Communication and pr: Made to measure. Disponível no site http://www.instituteforpr.com/measurement and evaluation.phtml, acessado em 3/21/05.

LINDENMANN, W. K. Guidelines and standards for measuring the effectiveness of PR programs and activities. Disponível no site http://www.instituteforpr.com/measurement_and_evaluation.phtml?article_id=2003_ guide_pr_effectiveness, acessado em 3/21/05.

MCELREATH, M. e BLAMPHIN, J. Partial answers to priority research questions. Journal of Public Relations Research, 6(2), 1994, p. 69-104.

MCLEOD, J. M. e CHAFFEE, S. H. Interpersonal approaches to communication research. In S. H. Chaffee e McLeod, J. M. (eds.). Interpersonal perception and communication. Special edition of American Behavioral Scientist, 16(4), 1973, p. 483-488.

MEYER, J. P. e ALLEN, N. Testing the side-best theory of organizational commitment: Some methodological considerations. Journal of Applied Psychology, 69, 1984, p. 372-378.

MINTZBERG, H. Power in and around organizations. Englewood Cliffs, NJ: Prentice-Hall, 1983.

MOLLEDA, J. C. International paradigms: The Latin American School of Public Relations. Journalism Studies, 2(4), 2001, p. 513-530.

Monsanto Corp. http://www.monsanto.com/monsanto/layout/our_pledge/ default.asp. (acessado em 21/3/05).

PIECZKA. M. Objectives and evaluation in Public Relations work: What do they tell us about expertise and professionalism? Journal of Public Relations Research, 12(3), 2000, p. 211-233.

PLOWMAN, K. Power in conflict for Public Relations. Journal of Public Relations Research, 10(4), 1998, p. 237-261.

ROGALL, N. Subaltern studies. Newsletter, 4, Autumn. London: London Socialist Historians Group, 1998, p. 2-3.

ROPER, J. Symmetrical communication: Excellent Public Relations or a strategy for hegemony? Journal of Public Relations Research, 12(1), 2005, p. 93-114.

SYNNOTT, G. e MCKIE, D. International issues in PR: Researching research and prioritizing priorities. Journal of Public Relations Research, 7(3), 1997, p. 163-186. 